
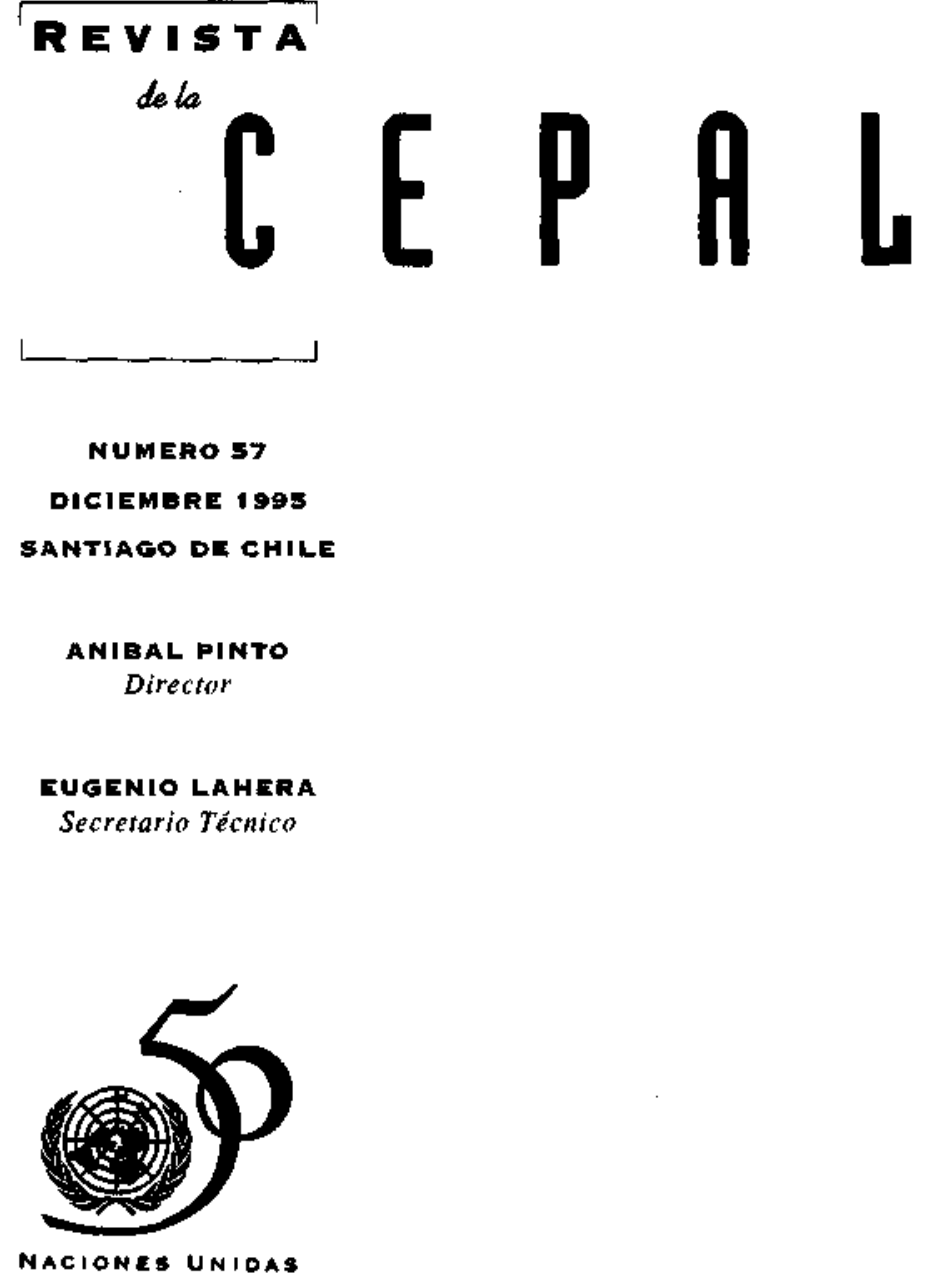
Las Naciones Unidas y la CEPAL en el

Cincuentenario de la Organización

Gert Rosenthal

La creación de las Naciones Unidas y de la CEPAL

Hernán Santa Cruz

Derechos humanos: el caso de los niños

Teresa Albánez

Gobernabilidad, competitividad e integración social

Fernando Calderón

Reforma laboral y equidad social:

la privatización de los puertos

Larry A. Burkhalter

Nuevas tendencias en las políticas salariales

Andrés E. Marinakis

Centroamérica: desempefio macroeconómico y

financiamiento social

Francisco Esquivel

Panamá y la integración económica centroamericana

Luis René Caceres

La dualidad del tipo de cambio en la economía cubana de los noventa

Archibald R.M. Ritter

Transnacionalización e integración productiva en

América Latina

Armando Di Filippo

Indice de autores y de temas en la Revista de la CEPAL, números 1 al 57

Orientaciones para los colaboradores de la Revista de la CEPAL 195 


\section{La dualidad del tipo de cambio en la economía cubana de los noventa}

Archibald R. M. RItter

Departamento de Ciencias Económicas y Escuela de Estudios Internacionales, Universidad de Carleton, Ottawa, Canadá.
En los años noventa se ha agudizado en la economía cubana la brecha entre el sector socialista tradicional regido por el peso y el sector internacionalizado, dolarizado y orientado al mercado. Esta división obedece, entre otras circunstancias, a la expansión del turismo y de las empresas extranjeras y mixtas; la contracción de la economía socialista y la pérdida de confianza en ella; el debilitamiento del peso por la acelerada inflación debida a lass emisiones monetarias para financiar el déficit fiscal, y la sobrevaluación del tipo de cambio. La coexistencia de dos monedas y la bifurcación estructural se han reflejado en la distribución del ingreso y han influido en el comportamiento económico de la población. Los cubanos que tienen acceso a dólares en el sector internacionalizado ganan más que el resto de la poblacion, por la diferencia entre el tipo de cambio paralelo y el oficial (comercial). Así, quienes desempeñan funciones sociales valiosas en el sector socialista de la economía reciben una menguada remuneración, mientras aquellos integrados al sector internacionalizado tienen ingresos relativamente adecuados. Esto hace que los cubanos procuren conseguir dólares por medios legales, semilegales o ilegales. Esta situación ha hecho resurgir problemas sociales que casi habían desaparecido a comienzos de los años sesenta. Ultimamente se ha logrado reducir el tipo de cambio paralelo y atenuar la bifurcación, gracias a ciertos cambios institucionales y la adopción de algunas políticas, sobre todo las de carácter fiscal que comenzaron a aplicarse en 1994. Se ha podido disminuir el déficit, desacelerar la emisión monetaria y controlar la inflación del peso, lo que incremento la demanda de esa moneda. Pero habrá que seguir profundizando este proceso de cambios para reunificar la economía, mediante medidas de política cambiaria, la mayor liberalización de la pequeña y mediana empresa y la desregulación de los precios. Esto úlcimo obligará también a reestructurar el sistema de seguridad social. 


\section{I}

\section{Introducción}

La economía cubana ha venido sufriendo una división cada vez más acentuada, sobre todo durante la primera mitad de los años noventa, entre el sector socialista tradicional regido por el antiguo peso, de un lado, y un sector internacionalizado y dolarizado creciente, vinculado a una economía nacional orientada al mercado y que opera en pesos, de otro. Las múltiples interacciones de estos dos sectores de la economía han creado un sistema de incentivos extremadamente disfuncional, que encauza el comportamiento económico de la población en forma antiproductiva, y da origen a muchas situaciones irracionales desde el punto de vista económico. La reunificación de la economía es indispensable para que los recursos humanos y naturales y el capital puedan utilizarse productivamente, objetivo que es de primordial importancia en vista de la grave crisis por la que atraviesa el país. Además, la integración en un sistema orientado al mercado es imprescindible para que la economía se recupere, y se den procesos de ajuste y transición.

La reunificación de los dos sectores de la economía exige una serie de cambios de políticas, proceso que será difícil a corto plazo, debido a factores económicos, políticos y sociales. Las áreas prioritarias deberían ser los tipos de cambio, el sistema monetario, la desregulación de los precios, la liberalización de las empresas, el control de las sociedades anónimas —empresas estatales autónomas- y la reestructuración del sistema de seguridad social. De hecho, la reunificación de la economía es un impor- tante factor de los procesos generales de ajuste y transición.

El objetivo del presente ensayo es analizar las características, el funcionamiento, el origen y las consecuencias de la bifurcación de la economía cubana en los años noventa, así como los cambios de políticas necesarios para reunificarla. En la sección II se describe la estructura dual de la economía cubana y se analiza su funcionamiento. En la sección III se presenta un análisis de las consecuencias económicas de la bifurcación. En la sección IV se examinan las medidas oficiales adoptadas durante la primera mitad de los años noventa para hacer frente a dicho fenómeno. $Y$, por último, en la sección $\mathrm{V}$ se describe las políticas que deben adoptarse para integrar los dos sectores en que se divide la economía.

El análisis estructural de la economía cubana en los años noventa es difícil, por la falta de datos concretos. A partir de 1989 el gobierno dejó de publicar información estadística detallada sobre la situación de la economía, como había hecho desde 1970 hasta 1989. ${ }^{1}$ En realidad, la bifurcación de la economía comenzó a hacerse evidente sólo en 1993. Algunos de los importantes cambios de políticas relacionados con este fenómeno -entre otros, la legalización del uso de dólares y del autoempleo, y la apertura de mercados agrícolas - comenzaron a adoptarse a mediados de ese año, de modo que se ha dispuesto de poco tiempo para reorganizar las actividades de recopilación y publicación de información que se realizan en los sectores público y privado.

$\square$ Muchas personas han aportado valiosos comentarios y críticas al presente ensayo, y han participado en discusiones informales sobre la actual situación economica de Cuba. Entre otros, deseo mencionar a Carl McMillan y Keith Acheson de la Universidad de Carleton (Ottawa); a Nobina y Keith Robinson, que actualmente se encuentran en La Habana; a Francisco León, Joseph Ramos, Jorge Katz, Juan Carlos Lerda y Michael Mortimore, de la CEPAL, en Santiago de Chile, y a analistas y observadores de la situación de Cuba. La responsabilidad por todas las interpretaciones, análisis y errores corresponde por cierto exclusivamente al autor.

\footnotetext{
- La situación es tal que, en la mayoría de los casos, la única fuente de información estadística de que disponen los analistas económicos de las universidades y los numerosos institutos de investigación para el estudio de la economía cubana es el periódico Gramma. Como es evidente, la calidad de los análisis económicos se ve afectada por esta reserva oficial, en un petíodo en que los análisis económicos adecuados son extremadamente importantes para la reformulación de la política económica. El obligar a los analistas cubanos a trabajar sin información adecuada dificulta sus intentos de contribuir a la comprensión de la economía, y redunda en un desaprovechamiento de su talento y sus energías.
} 


\section{II}

\section{Dualismo monetario en la economía cubana}

A comienzos de los años noventa, la principal característica de la estructura económica cubana era su división en un sector socialista tradicional regido por el peso, y un sector internacionalizado y dolarizado. El primero se encontraba en un estado de profunda crisis y desorganización, y se veía afectado por falta de confianza y un abandono generalizado. Por su parte, la economía internacionalizada y dolarizada iba expandiéndose rápidamente pese a la recesión, debido a la importancia creciente del turismo y la inversión extranjera, algunos cambios de políticas y el vacío dejado por la contracción del sector tradicional regido por el peso. La expansión de la economía internacionalizada se tradujo, en primer lugar, en un aumento de las actividades dolarizadas, incluidos el turismo, la participación extranjera en empresas mixtas, la producción de bienes y servicios de apoyo, y las remesas de dólares desde el extranjero. $\mathrm{Y}$ en segundo lugar, en el surgimiento de actividades económicas intermedias o de transicion orientadas al mercado o a un cuasimercado, incluidos el autoempleo, tanto en la economía oficial como en la paralela y en actividades vinculadas a mercados.

\section{Características y funcionamiento}

A mediados de 1995, la economía socialista tradicional regida por el peso abarcaba prácticamente todas las ramas de actividad, con la excepción de los trabajadores por cuenta propia en actividades artesanales e industriales y algunas empresas mixtas de exportación. También formaban parte de este sector la mayoría de los servicios, incluidos todos los financieros; gran parte de los comerciales; algunos servicios personales, con la excepción de los prestados en forma independiente; la mayor parte del comercio al por mayor y al detalle, con la excepción de los mercados de productos agrícolas, industriales y artesanales; la mayoría de los servicios de transporte, y todos los servicios de comunicaciones. El papel de la economía socialista tradicional en el sector agrícola sufrió una profunda transformación a raíz del establecimiento de las unidades básicas de producción cooperativa (UBPC) a mediados de 1993. La creación de estas cooperativas se tradujo en una baja de la participación estatal en el sector agrícola de $75 \%$ a $35 \%$, en tanto que la proporción de tierra cultivada en manos del Estado bajó de $80 \%$ a $25 \%$ (cuadro 1). En cambio, el Estado sigue desempeñando una importante función en la provisión de insumos, la prestación de servicios de apoyo y la adquisición de las cuotas establecidas de ciertos productos a precios regulados. Aún no se sabe qué grado de autonomía llegarán a tener las UBPC y si serán auténticas cooperativas, pero estos cambios pueden influir notablemente en el sistema de tenencia de la tierra en Cuba.

CUADRO I

Cuba: Tenencia de la tierra, marzo de 1994

\begin{tabular}{|c|c|c|c|c|c|}
\hline \multirow{2}{*}{ Superficie } & \multirow{2}{*}{ Hectáreas } & \multicolumn{4}{|c|}{ Participacion por sectores $(\%)$} \\
\hline & & Estatal & Cooperativo & Privado & $\mathrm{UBPC}^{\mathrm{a}}$ \\
\hline Total & 11048000 & 55.5 & 7.5 & 9.8 & 27.2 \\
\hline \multicolumn{6}{|l|}{ Dedicada a la } \\
\hline agricultura & 6741000 & 34.0 & 11.0 & 14.0 & 41.0 \\
\hline Cultivada & 4723000 & 25.0 & 9.0 & 11.0 & 55.0 \\
\hline Regada & 964000 & 25,0 & 8.0 & 6.0 & 61.0 \\
\hline \multicolumn{6}{|l|}{ Con cultivos de: } \\
\hline Caña de aź́car & 1918000 & 9.0 & 12.0 & 2.0 & 77.0 \\
\hline Arroz & 191000 & 41.0 & 9.0 & 12.0 & 38.0 \\
\hline Legumbres y tubérculos & 524000 & 16.0 & 15.0 & 48.0 & 21.0 \\
\hline Tabaco & 57000 & 11.0 & 12.0 & 49.0 & 28.0 \\
\hline
\end{tabular}

Fuente: CONAS, 1994, p. 75.

a Utidades básicas de producción cooperativa. 
Hasta 1990 la asignación de recursos en el sector socialista tradicional se realizaba en el marco del sistema de planificación centralizada. Por lo tanto, el volumen, la composición y el destino de la producción de las empresas; la composición y el origen de los insumos; las modalidades de inversión dentro de cada sector y rama de producción y entre ellos, así como la naturaleza de los vínculos externos de las empresas, estaban determinados por el Plan. La imposibilidad de planificar todos estos aspectos se traducía en mucha improvisación y una gran dependencia del "sociolismo", es decir, la solución de problemas económicos mediante un intercambio de favores en círculos de amigos. El sistema se fue deteriorando a raíz de los problemas de los años noventa, y fue siendo sustituido por la improvisación y un "sociolismo" cada vez más generalizado. En este sector de la economía, la distribución de bienes de consumo se realizaba mediante el racionamiento de ciertos alimentos básicos y artículos para el hogar, aunque el número de productos racionados se redujo entre 1990 y 1994. Los automóviles, las viviendas, los bienes duraderos y los viajes al extranjero, se asignaban por merecimientos políticos.

El precio de casi todos los bienes de consumo distribuidos mediante el sistema de racionamiento era casi el mismo de 1960-1962. La asignación de los recursos humanos a distintos sectores, ramas de la industria y actividades no se regía por el funcionamiento descentralizado del mercado, sino que respondía a decisiones del gobierno central, aunque en algunos casos los estudiantes podían elegir la carrera que deseaban seguir y el área en que preferían trabajar, y el Estado ofrecía trabajo a todos los que se incorporaban a la fuerza laboral en un campo relacionado con sus estudios. Los ingresos de los integrantes de este sector se limitan a una escala muy reducida de sueldos y salarios (de 80 a 480 pesos al mes), pero, a modo de complemento, los trabajadores pueden comprar los artículos asignados con criterios políticos a precios muy bajos. Ultimamente, los trabajadores de ciertos sectores importantes (generación de electricidad, producción de petróleo, algunas ramas del sector pesquero, actividades portuarias) también han visto complementado su salario con pagos en divisas y, desde diciembre de 1994, en pesos "convertibles".

El sector internacionalizado y dolarizado de la economía cubana está integrado por el turismo y los servicios de apoyo, las empresas extranjeras asociadas con cubanos en empresas conjuntas, algunas empresas mixtas grandes y las sociedades anónimas. Es- tas últimas son conglomerados de propiedad estatal, autónomas desde el punto de vista financiero y administrativo, que operan en este sector de la economía y actúan en forma muy similar a las empresas privadas. A mediados de los años noventa, algunas empresas estatales han empezado a trabajar para el sector turismo, que les paga en divisas; asimismo, se han creado explotaciones agrícolas que producen legumbres para el sector turismo y cobran en dólares. También forman parte de este sector de la economía los receptores de dólares del exterior, que gastan en la economía interna de mercado, en tiendas que operan exclusivamente con dólares. Otro componente de este sector es la economía interna de mercado, integrada por trabajadores independientes registrados o no registrados; los mercados de productos agrícolas, artesanales e industriales y, en mucha menor medida, las UBPC. El sector agrícola privado es otra de las áreas que integran este sector; aunque representa el $14 \%$ de las tierras dedicadas a la agricultura, es posible que genere una mayor proporción del valor agregado agrícola, debido a que produce un porcentaje desproporcionado de productos de alto valor, como los tubérculos y el tabaco (cuadro 1).

Ya se ha hecho referencia al importante papel que desempeñan en la agricultura las UBCP, cuya evolución no está clara todavía, pero que posiblemente se encuentren en una etapa inicial de transición. La prestación de algunos servicios personales se realiza a través de los mecanismos del mercado y a precios que determinan las fuerzas que operan en éste. Los trabajadores independientes producen una alta proporción de artículos artesanales, pero no tienen una participación tan importante en el empleo y el valor agregado del sector manufacturero y la industria. Al parecer, aún no se dispone de datos sobre la nueva estructura del empleo y el valor agregado, que están sufriendo una acelerada transformación, clasificados en sector público y privado y en actividades integradas o no integradas al mercado.

En este sector de la economía, la asignación de recursos está determinada, al menos en parte, por los mecanismos del mercado. En los casos de los trabajadores independientes y de las transacciones que se realizan en los mercados de productos agrícolas, artesanales e industriales, los precios dependen de la oferta y la demanda; el ingreso a estos mercados, que suelen ser muy competitivos, es relativamente fácil. Los precios de los artículos artesanales están denominados en pesos o en dólares, al tipo de cambio paralelo, $\mathrm{y}$ las transacciones pueden realizarse en ambas mone- 
das. En cambio, la ley exige que en los mercados de productos agrícolas e industriales todas las transacciones se realicen en pesos, aunque los cambistas cambian dólares por pesos en forma expedita y al tipo de cambio paralelo vigente. A los trabajadores independientes se les puede pagar en dólares o en pesos, también al tipo de cambio paralelo. En el sector turismo y el de empresas extranjeras, todas las transacciones se realizan en dólares. Las tiendas que operan con dólares absorben parte de los dólares y pesos "convertibles" en circulación y dejan cuantiosas utilidades al Estado, equivalentes a un impuesto; actualmente participan en esta actividad varias cadenas que importan alimentos, prendas de vestir, calzado, artefactos, aparatos eléctricos y otros bienes duraderos, incluso caramelos y bebidas no alcohólicas y alcohólicas, así como restaurantes para extranjeros y cubanos.

Las remuneraciones y las ganancias en este sector están determinadas en gran medida por las fuerzas del mercado. El ingreso de los trabajadores independientes, legales o ilegales, depende de la relación entre la demanda de los bienes y servicios que venden, por una parte, y la competencia y los costos de producción, por otra. Este grupo está integrado por las 166 categorías de trabajadores por cuenta propia cuyas actividades se legalizaron a partir del 12 de junio de 1995; los trabajadores independientes que realizan actividades correspondientes a las categorías legalizadas, pero que no se han registrado, y los que venden bienes y servicios que siguen siendo ilegales, como ocurre con algunos servicios profesionales. Las propinas en divisas son la principal fuente de ingresos de los trabajadores del sector turismo y de los que prestan servicios de apoyo. En el sector de empresas extranjeras, los factores externos de producción tienen que recibir remuneración en dólares, porque de lo contrario no tendrían incentivos para operar en Cuba. Se supone que a los empleados cubanos de empresas extranjeras se les paga en pesos; los pagos suplementarios en dólares son ilegales, pero no es fácil impedirlos cuando son la única posibilidad que tienen las empresas de no perder a sus empleados. Las remesas en dólares no son un pago por servicios prestados, sino regalos de familiares que viven en el extranjero.

\section{Causas de la bifurcación de la economía cubana}

La división de la economía cubana en los dos sectores señalados, responde sobre todo a las políticas eco- nómicas y la estructura institucional de la economía, a las que se suma el proceso de apertura económica.

La bifurcación provocada por la interacción de estos factores se dio de la siguiente manera: en primer lugar, el Estado distribuye bienes y servicios racionados a precios bajos y regulados, por lo que la remuneración de la mano de obra siempre ha sido superior al valor de éstos. La diferencia entre las remuneraciones y el valor de los bienes y servicios racionados disponibles aumentó considerablemente entre 1989 y 1994 , en tanto que el volumen producido se redujo. Esta diferencia se fue acentuando cada vez más debido a la regulación de los precios, que impedía que éstos aumentaran, y a la disposición del gobierno a cubrir el creciente déficit operativo de las empresas estatales mediante subsidios financiados con emisiones monetarias o la concesión de créditos que eran incobrables. Por lo tanto, la emisión de antiguos pesos con este objeto provocaba el proceso inflacionario que se ha descrito.

En segundo lugar, la diferencia percibida por los trabajadores se canalizaba al mercado negro, por 10 que el precio de los bienes y servicios que se transaban en ese sector de la economía tendía a subir. Los precios siguieron subiendo aun después de que se legalizaron algunas de las actividades que se realizaban fuera de la economía socialista controlada. Este aumento de los precios es por definición un proceso inflacionario, aunque las autoridades afirmaban hasta hace poco tiempo que no había inflación gracias a la regulación de los precios de los bienes y servicios racionados. En tercer lugar, la inflación sostenida y acelerada provocó una creciente devaluación del peso con respecto al dólar. Al intensificarse la inflación real, los cubanos empezaron a perder confianza en el peso y a recurrir al dólar como medio de intercambio monetario.

A mediados de 1994, el dólar alcanzó un valor máximo de 100 a 120 pesos en el mercado paralelo; es posible que esta devaluación del peso se haya debido a los siguientes factores: i) la elevada demanda de dólares de los "balseros" interesados en vender sus pertenencias y colocarlos fuera del país o destinarlos a comprar balsas, ii) la grave escasez de artículos que podían comprarse en pesos y iii) el pesimismo, la pérdida de confianza y la desesperanza crecientes de muchos cubanos ante el futuro económico del país. A continuación, el tipo de cambio paralelo registró una leve baja, especialmente después de la apertura de los mercados de productos agrícolas a partir del $1^{\circ}$ de octubre de 1994 , que se tradujo en un aumento de la demanda de pesos y en una dismi- 
nución del precio de los alimentos con respecto al nivel que habían alcanzando en el mercado negro. En abril de 1995, el tipo de cambio llegó a un nivel mínimo de 30 a 35 pesos por dólar, pero en junio de 1995 parecía ir aumentando nuevamente. Aun así, la diferencia entre el tipo de cambio oficial ( 1 peso por dolar en el sector turismo y 0.74 pesos por dólar en el sector comercial) es la más alta que se ha registrado.

La política cambiaria y el proteccionismo han contribuido notablemente a la bifurcación de la economía cubana. El tipo de cambio vigente en el sector socialista es de 0.74 pesos por dólar, por lo que los productos importados son extremadamente baratos si se calcula su precio en pesos. Esto puede llegar a generar una altísima demanda de productos importados, que superaría con creces los bienes que podrían adquirirse con las entradas en divisas de Cuba. Por consiguiente, se ha recurrido a la adopción de controles burocráticos (barreras no arancelarias), que ofrecen ilimitadas posibilidades de protección contra algunas importaciones o que posibilitan la importación de productos tales como medicamentos y alimentos al tipo de cambio oficial, para que los consumidores cubanos sigan comprándolos a precios bajos en pesos. Estas barreras no arancelarias de carácter burocrático han ofrecido al sector socialista de la economía una protección ilimitada y absoluta contra las importaciones competitivas de productos finales. A la vez, se ha autorizado el ingreso al país de insumos, repuestos, maquinarias y equipos exentos de aranceles, lo que equivale a la concesión de un importante subsidio a las empresas con derecho a importar al tipo de cambio oficial. Por otra parte, si las empresas del sector socialista tradicional de la economía cambian los dólares recibidos por sus exportaciones al tipo de cambio oficial, sus ganancias son muy limitadas, por lo que no tienen incentivos para incrementar y diversificar sus exportaciones.

Las sociedades anónimas, que son grandes conglomerados dolarizados, también utilizan los tipos de cambio oficiales; pero como muchas de ellas funcionan parcial o totalmente en el sector internacionalizado (turismo, tiendas que operan con dólares, exportaciones e importaciones o prestación de servicios a empresas extranjeras, al servicio diplomático o a organizaciones internacionales) tienen derecho a importar productos básicos a los que no se aplican aranceles. Estos productos importados se venden, entre otros, a turistas, a cubanos que manejan dólares y a empresarios extranjeros; están exentos de aranceles, pero en muchos casos se les aplica un recargo, que en la práctica constituye un impuesto. Se han adoptado normas y disposiciones con el objeto de contrarrestar la marcada preferencia de las sociedades anónimas por las importaciones y fomentar la compra de productos nacionales.

Por no formar parte de ninguna de las áreas prioritarias de la economía, las microempresas no tienen derecho a importar insumos a los tipos de cambios oficiales; tampoco han organizado grupos que defiendan sus intereses y presionen al gobierno para que les permita hacerlo. De hecho, las microempresas ni siquiera tienen derecho a importar directamente del extranjero al tipo de cambio del mercado negro, aunque pueden llegar a adquirir insumos importados ya ingresados al país.

Cuba se encuentra así en una situación paradójica: tiene un sistema muy variable y discriminatorio de protección efectiva y concesión de subsidios a las importaciones mediante barreras no arancelarias de carácter burocrático, y la vez emplea un tipo de cambio extremadamente sobrevalorado. En este contexto se dan las siguientes situaciones: i) la economía socialista tradicional se enfrenta a barreras no arancelarias muy variadas, a lo que se suma la sobrevaloración; ii) la economía de mercado de transición se enfrenta a barreras no arancelarias casi infinitas, y iii) muchas de las sociedades anónimas que perciben ingresos en divisas tienen derecho a importar libremente un gran número de bienes a un tipo de cambio oficial muy favorable.

Por último, la expansión del turismo y la creciente participación de las empresas extranjeras desde el comienzo de los años noventa han contribuido al crecimiento de la economía internacionalizada y dolarizada. Entre 1990 y 1993, el número de turistas aumentó de unos 340000 a 550000 , en tanto que las entradas brutas provenientes del turismo se incrementaron de 189 a 720 millones de dólares, aunque el valor agregado en Cuba ascendió apenas a alrededor del $30 \%$ del ingreso bruto en 1994, de acuerdo a lo informado por funcionarios del Ministerio de Turismo (16 de febrero de 1995). También ha ido en aumento el número de empresas extranjeras que han abierto filiales en Cuba o han creado empresas mixtas con firmas estatales. Se exige a los turistas, $y$ a los empresarios y comerciantes extranjeros, que operen en dólares. 


\section{III}

\section{Consecuencias de la bifurcación de la economía}

\section{Distribución del ingreso y sistema general de incentivos}

La consecuencia más importante, y más conocida, de la bifurcación de la economía cubana es la relacionada con la distribución del ingreso y el sistema general de incentivos. En la economía socialista tradicional, los sueldos y salarios fluctúan entre 80 y 480 pesos al mes aproximadamente. Estos sueldos y salarios equivalen a entre 2 y 12 dólares por mes si se calculan al tipo de cambio paralelo ( 40 pesos por dólar a comienzos de 1995); si se convierten al tipo de cambio comercial $(0.74$ pesos por dólar) son mucho más altos, aunque este último prácticamente no existe y no puede ser utilizado por particulares.

Por otra parte, quienes perciben ingresos en divisas o reciben divisas del extranjero, especialmente dólares, tienen ingresos más altos; este grupo está integrado por quienes prestan servicios de apoyo o servicios fuera de Cuba pagados en divisas, los trabajadores del sector turismo y las empresas extranjeras, $y$ las personas que reciben remesas de familiares residentes en el extranjero. Por ejemplo, un cantinero o un ascensorista que trabaje en el sector turismo puede llegar a ganar, como promedio, unos 30 dólares mensuales, suma que podría equivaler a 1200 antiguos pesos y representar hasta un $1000 \%$ del ingreso en pesos de una persona con una preparación similar que trabaje en otros sectores y hasta un $250 \%$ del nivel superior de la escala de sueldos y salarios en pesos. Un ingeniero que trabaje como taxista no registrado en su auto particular puede llegar a ganar de 50 a 150 dólares por mes, e incluso mucho más, lo que equivale a unos 2000 a 6000 pesos antiguos o de 8 a 20 veces el ingreso en pesos que puede percibir un cubano en la economía socialista tradicional. Estos casos son sólo algunos de los muchos que se dan actualmente.

Los trabajadores por cuenta propia y quienes ofrecen sus bienes y servicios en el mercado también tienen entradas más altas; esto se debe a que los precios que cobran están determinados por los mecanismos del mercado y a que la demanda de éstos proviene del excedente de que dispone la mayoría de los cubanos después de comprar productos básicos racio- nados con parte del ingreso percibido en antiguos pesos. Sin embargo, esos precios y, por lo tanto, el ingreso de los trabajadores independientes, están limitados por la relativa "libertad de incorporación" en actividades registradas o no registradas, de tal modo que se mantienen a un nivel bajo debido a la competencia entre numerosos trabajadores de esa categoría. Las escasas barreras a la incorporación, unidas al aumento del número de posibles nuevos integrantes del sector de microempresas debido a la reducción actual y prevista de las empresas estatales, los servicios públicos y algunas de las ramas de actividad profesional, deberían traducirse en precios e ingresos aún más bajos en el futuro.

En pocas palabras, los ingresos percibidos por los integrantes de la economía internacionalizada suelen ser superiores a los que se reciben en la economía socialista tradicional. Aunque la diferencia real puede ser menor que la diferencia aparente y nominal en antiguos pesos, suele ser bastante amplia. El ingreso en antiguos pesos permite comprar alimentos básicos racionados, pero en 1994 la cuota mensual sólo alcanzaba para una o dos semanas, lo que provocaba graves problemas de escasez. El ingreso en antiguos pesos también permitía comprar otros productos racionados, como artículos de tocador y limpieza, y unas pocas prendas de vestir por año. En cambio, para comprar alimentos en los mercados de productos agrícolas, o en el mercado negro hasta el $1^{\circ}$ de octubre de 1994, y en los mercados de productos industriales y artesanales, hay que disponer de una gran cantidad de antiguos pesos, dado que los precios están determinados por el mercado. Como es evidente, para comprar alimentos, productos de tocador, prendas de vestir, calzado y bienes duraderos de consumo en las tiendas que operan en dólares, hay que disponer de dólares o pesos "convertibles".

Como es natural, esta estructura de distribución del ingreso supone una serie de incentivos que influyen en las actividades remuneradas que se desempeñan. En vista de que el valor real del ingreso es inferior en la economía socialista tradicional que en la economía internacionalizada y dolarizada y en la economía orientada al mercado, la mayoría de los cubanos prefieren estos dos últimos sectores. Lo que ocu- 
Tre en realidad es que prefieren ganar dólares. En la práctica esto significa, por ejemplo, que profesores de inglés $o$ de cualquier otro idioma que se hable en el sector turismo dejan de enseñar para trasladarse a ese sector; que jóvenes que deberían concentrarse en sus estudios con la idea de trabajar en el sector público o de desempeñarse como profesionales se convierten en "jineteros" o "jineteras"; que hay casos de enfermeras que dejan de trabajar como tales para ganar dólares, etc. Incluso quienes tienen un buen trabajo en la economía socialista tradicional se ven obligados a dedicarse a actividades independientes o a la prestación de servicios a jomada parcial para ganar $o$ conseguir dólares o una gran cantidad de antiguos pesos.

Quienes desempeñan funciones muy importantes para la sociedad en la economía socialista tradicional, en los sectores de la educación y la salud, y en la agricultura y la industria, entre otros, no reciben mayores incentivos; en cambio, otras actividades, algunas de las cuales son menos valiosas para la sociedad, como la venta de cigarros en las calles, ofrecen mayores alicientes. En realidad, no deja de ser irónico que los más ardientes partidarios del régimen revolucionario y sus principales beneficiarios en la economía socialista tradicional (soldados, obreros, profesionales de los sectores de salud y educación) sean los que han tenido más problemas económicos. Los cubanos que han mantenido buenas relaciones con sus parientes en el extranjero, los pequeños empresarios y los vendedores de distinto tipo reciben altos ingresos en dólares o mediante un trabajo independiente mejor remunerado que los demás.

\section{Consecuenclas de la asignación de recursos: fuerzas del mercado, "microirraclonalidades" y disfuncionalidades}

Los altos ingresos que perciben quienes abandonan la economía socialista tradicional para orientarse hacia la economía internacionalizada y dolarizada, y los importantes incentivos que éstos suponen, responden a un fenómeno que tiene su origen en el mercado. En ciertos sentidos, ésta es una respuesta normal o natural a la creciente importancia que han ido adquiriendo las divisas y las importaciones desde que Cuba perdió de $70 \%$ a $75 \%$ de su capacidad para importar. La reorientación de recursos hacia el sector turismo, el sector que atrae divisas, es un aspecto indispensable del proceso de ajuste estructural del país que puede contribuir al incremento de las entradas en divisas y de las importaciones. Se dice que esta reorientación tiene su origen en el mercado, debido a que la escasa disponibilidad de productos importados de todo tipo es un factor que contribuye a una marcada alza del tipo de cambio en el mercado negro.

Lamentablemente, algunos de los sectores que generan un mayor volumen de divisas -entre otros, los productores de azúcar, cítricos y café- forman parte de la economía socialista tradicional, de modo que reciben entradas en pesos al tipo de cambio comercial oficial de 0.74 pesos por dólar. A diferencia de lo que ocurre con el turismo, estos sectores no se ven beneficiados por las divisas que aportan al país. Sus bajos ingresos reales se traducen en una escasez de insumos de todo tipo, especialmente de artículos importados como repuestos, nuevos equipos e insumos intermedios. Otras consecuencias de esta situación son el constante deterioro de los bienes de capital y, sobre todo, la pérdida de recursos humanos, dado que los trabajadores renuncian a su empleo en el sector tradicional regido por el peso, con el proposito de ganar dólares o más pesos trabajando en forma independiente. Es indudable que la grave discriminación de que es objeto la mayoría de los sectores generadores de divisas, debido al dualismo monetario existente en la economía, es una de las irracionalidades más destructivas de la economía cubana actual, que se caracteriza por una urgente necesidad de divisas.

Aunque la reorientación de recursos al sector internacionalizado y a la economía nacional de mercado tiene fundamentos lógicos, el funcionamiento de la economía también presenta múltiples "microirracionalidades", que se suman a la extrema disfuncionalidad de esta área. Debido a que los precios están regulados y son extremadamente bajos en la economía socialista tradicional, es posible adquirir diversos bienes y servicios a precios regulados y revenderlos a precios más altos determinados por el mercado, ya sea en pesos o en dólares al tipo de cambio del mercado negro. Asimismo, ya sea a través del robo o de otras maniobras ilegales, algunos productos básicos que se transan en la economía socialista se venden a precios muy altos definidos por el mercado. Este fenómeno es muy común. Por ejemplo, el ron que se compra a precios regulados, en antiguos pesos, se puede revender a un precio mucho más alto. La reventa de prácticamente todos los alimentos que se compran a precio oficial deja grandes ganancias. La gasolina que se compra en pesos a precio de producto racionado también se puede revender en dólares y todo producto importado al tipo de cambio comercial 
oficial puede venderse en el mercado negro o en dólares a precios mucho más altos.

La reacción ante la inmensa variedad de posibilidades de ganar dinero que ofrecen los controles de precios y la importación de productos al tipo de cambio oficial es una búsqueda generalizada de lucro. La compra y venta de productos de un sector de la economía en el otro deja grandes ganancias a quienes dedican sus energías económicas creativas a esas operaciones. De hecho, son tan altas las ganancias que deja la compra de un artículo en pesos en la economía socialista y su reventa en la economía internacionalizada o nacional de mercado, que muchas personas prefieren renunciar a un puesto permanente o simplemente no presentarse a trabajar, para dedicarse a actividades lucrativas. Debido a esta actitud tan pragmática, se da escasa importancia al trabajo productivo y, a la vez, se dedica una cantidad desproporcionada de energías a las operaciones de compra y venta, algunas de las cuales serían superfluas o tendrían un valor limitado en circunstancias normales.

La segunda irracionalidad es el alto costo real para la sociedad cubana de la reasignación de recursos humanos a la economía internacionalizada. Si bien esta reasignación es necesaria en las actuales circunstancias, su costo es excesivo en la estructura monetaria dual de mediados de los años noventa. Por ejemplo, ¿es lógico que se pague a los médicos, las enfermeras y los obreros del sector industrial en antiguos pesos y de acuerdo con la antigua estructura de sueldos y salarios, cuando las propinas que reciben los trabajadores no calificados del sector turismo les permiten tener un ingreso mucho más alto? Aunque es difícil formular juicios de valor como éste, parecería que la sociedad cubana destina un gran volumen de recursos reales a dar incentivos y remunerar a los integrantes de la economía dolarizada, mientras quienes forman parte de la economía de precios regulados y regida por el peso disponen de un ingreso muy limitado.

\section{Consecuenclas sociales de la bifurcación}

La bifurcación de la economía cubana, estrechamente vinculada a la baja del ingreso real per cápita desde 1989 , ha tenido una serie de consecuencias sociales negativas, entre otras las relacionadas con la distribución del ingreso, los hábitos de trabajo y el afán de lucro, con las dificultades para mantener el sistema único de prestación de servicios sociales básicos y con el resurgimiento de problemas que prácticamente se habían eliminado en los primeros años del régimen revolucionario.

Como ya se ha indicado, la bifurcación del sistema monetario ha tenido efectos muy negativos en la distribución del ingreso. A partir de 1993, quienes no tienen acceso a dólares y trabajan en la economía socialista se han visto perjudicados y reciben ingresos mínimos. En cambio, quienes ganan o reciben dólares y quienes perciben un ingreso en pesos determinado por el mercado están en general en mejores condiciones. Cabe añadir que quienes tienen acceso privilegiado a ciertos artículos importados al tipo de cambio oficial —como automóviles y gasolina-, y los que tienen ciertas posibilidades de consumo gracias a su vinculación con importantes instituciones, también están relativamente bien, al igual que antes de 1990. Esta estructura de distribución del ingreso, en virtud de la cual las personas que prestan servicios valiosos para la sociedad en el sector tradicional de la economía reciben ingresos muy bajos, constituye de hecho un problema social. Por otra parte, quienes actúan como intermediarios entre las dos economías pueden ganar mucho por servicios que serían superfluos y no reportarían ganancias si la economía cubana no estuviera bifurcada.

Otra consecuencia de la bifurcación que se ha producido con la baja de los ingresos reales es el resurgimiento de la mendicidad, los vendedores ambulantes, la prostitución o la semiprostitución, y la delincuencia en gran escala, que habían desaparecido o se habían reducido a un mínimo a mediados de los años sesenta. En 1994 los cubanos se acercaban a los extranjeros, que al parecer identificaban fácilmente, para pedirles dólares. En La Habana la mayoría de los mendigos son niños, pero también hay jubilados y madres con niños; al parecer no son "pordioseros profesionales" como los que se ve comúnmente en algunos países asiáticos. Más bien da la impresión de que algunos adultos mendigan esporádicamente cuando se encuentran en una situacion desesperada, en vista de que cada dólar que reciben de esta manera equivale a 30 o 35 antiguos pesos, lo que para muchos representa el salario de una semana o más. En algunos casos, los niños que mendigan provienen de familias pobres, pero hay muchos que piden limosna para comprar caramelos, bebidas y otros productos importados, que se venden en máquinas y quioscos de propiedad de sociedades anónimas.

El comercio callejero semilegal o ilegal ha adquirido enormes proporciones. Los jóvenes que se dedican a estas actividades, conocidos como "jinete- 
ros", revenden cajas de cigarros, botellas de ron y "medicamentos", y actúan como proxenetas o como acompañantes en el área internacionalizada de la economía. Las "jineteras" trabajan como prostitutas o acompañantes, actividades que les reportan altos ingresos. Al parecer, la mayoría de estos jóvenes de ambos sexos sólo dedican parte de su tiempo y sus energías a estas actividades, sobre las que se dispone de escasa información confiable, pese a su alcance y a su carácter conspicuo. ${ }^{2}$

A juzgar por lo que se observa en la práctica, parecería que la delincuencia ha aumentado notablemente. Los comentarios de la gente y las medidas de seguridad que se aplican en el sector internacionalizado, así como las precauciones que toma mucha gente en La Habana, permiten pensar que la profunda diferencia existente en materia de ingresos entre el sector socialista tradicional y el sector internacionalizado inducen más que nunca al robo. Lamentablemente, no hay datos estadísticos que permitan corroborar esta afirmación.

Por último, la bifurcación de la economía y la contracción económica dificultan el mantenimiento de sistemas únicos de educación y salud de buena calidad. Los servicios de salud pública se han deteriorado notablemente, debido a la falta de insumos importados, las bajas asignaciones presupuestarias y el elevado ausentismo del personal de los hospitales. La escasez de medicamentos también es muy común en el sector de la economía regido por el peso; por lo tanto, los pacientes que disponen de dólares optan por adquirirlos en las tiendas que operan en esa moneda o por comprar los alimentos y los implementos que los hospitales no ofrecen. Es poco probable que muchos médicos estén trabajando fuera del sistema estatal de salud y cobrando en dólares o aplicando tarifas determinadas por el mercado. Esta actividad es ilegal y se ha prohibido explícitamente a los médicos que ejerzan su profesión en forma privada o independiente. Sin embargo, como ocurría ya mucho antes de la revolución, parecería que en algunas zonas los médicos reciben pagos en especie. En todo caso, es cada vez más difícil evitar la transición gradual hacia un sistema dual de salud, sistema que se opondría abiertamente a las intenciones del régimen de ofrecer los mismos servicios médicos a toda la población. Por lo que se observa directamente, los servicios de educación también parecen haber sufrido un deterioro, dado que el interés en ganar dólares o complementar el sueldo con entradas en antiguos pesos lleva a los maestros a dedicar menos tiempo y energías a la enseñanza. Por consiguiente, cada vez es más común que los padres de familia les den clases a sus hijos o paguen por clases privadas.

\section{IV}

\section{Reunificación de la economía (1993-1995)}

Al parecer, el gobierno sólo tomó plena conciencia del grado de bifurcación monetaria de la economía cubana después de autorizar el uso de dólares a mediados de 1993. Es posible que esta medida haya facilitado la comprensión del fenómeno y sus conse-

\footnotetext{
2 Mirta Rodríguez Calderón, periodista y cofundadora de MAGiN (Asociación de Mujeres Comunicadoras) ha insistido en que el "jineterismo" que ejercen algunas jóvenes cubanas no es necesariamente de caracter sexual y que, por lo tanto, es muy diferente de la prostitución que se ejercía antes de 1959 . En muchos casos, las jineteras simplemente van a cenar, a bailar o a escuchar conciertos con sus clientes, los acompañan en paseos o excursiones turísticas. o los llevan a las tiendas que operan en dólares, aunque siempre cobran por el tiempo que les dedican. La posibilidad de casarse con un extranjero e irse del país es muy atractiva para algunas jovenes. Los varones jóvenes que ofrecen servicios similares de compañía pueden llegar a casarse con una extranjera y emigrar (Strout, 1995, p. 3).
}

cuencias, aunque la bifurcación ya existía de hecho desde mediados de los años ochenta y comenzó a agravarse a partir de 1990. Cabe señalar que en algunos de los análisis más importantes de la economía cubana realizado hasta 1994 no se encuentran referencias ni descripciones del fenómeno (Carranza, 1993, y Lee, 1993, entre otros). La designación del Dr. José Luis Rodríguez como Ministro de Hacienda puso en evidencia la creciente inquietud del gobierno ante el aumento del déficit fiscal y sus repercusiones. El respaldo con que contaba el Dr. Rodríguez cuando asumió el cargo y la adopción en la Asamblea Nacional de una serie de medidas destinadas a reducir el déficit fiscal indica que en 1994 se comprendía mejor tanto las causas como las consecuencias negativas de la bifurcación. 
Las reformas iniciadas durante el segundo semestre de 1993 han desacelerado o revertido parcialmente el proceso de bifurcación.

\section{Políticas fiscales}

El conjunto de medidas adoptadas en 1994 por el Ministerio de Hacienda con el objeto de reducir el déficit fiscal han contribuido a atenuar la tendencia a la bifurcación. La reducción del déficit de alrededor de 5100 millones de pesos en 1993 (probablemente el $28 \%$ del PIB estimado) a una cifra estimada en 1400 millones en 1994 (alrededor de 7 a 8\% del PIB) (véanse en el cuadro 2 los principales indicadores económicos para el período 1985-1995), se tradujo en una notable disminución de las emisiones de dinero destinadas a cubrir el déficit (Gramma International, 1995, p. 4). A consecuencia de esto, disminuyó la corriente de antiguos pesos inyectados en la economía que no eran absorbidos por los bienes y servicios a precios regulados; a su vez, esto mitigó la presión al alza de los precios del mercado negro o determinados por el mercado y del precio del dólar en el mercado negro. En caso de que el aumento de los impuestos y los recortes de gastos permitan que el déficit fiscal siga disminuyendo en 1995, el alza de los precios no controlados y del tipo de cambio paralelo del dólar debería mitigarse.

A continuación se enumeran algunas de las medidas fiscales destinadas a reducir los gastos e incrementar las entradas:

- Reducción de los subsidios a las empresas, de 5400 millones en 1993 a un nivel previsto de 2200 millones en 1995, mediante alzas de los precios y la adopción de estrictas medidas para fomentar el autofinanciamiento.

- Alza del precio de artículos como los cigarrillos, los cigarros y el ron.

- Alza de las tarifas de los servicios públicos (electricidad, teléfonos, transporte, correos).

- Eliminación de los subsidios a los comedores de las empresas y las escuelas, la provisión de suplementos vitamínicos y la enseñanza de idiomas, y el cobro de una tarifa por esos servicios.

- Cobro de entrada a eventos deportivos, museos y galerías de arte.

- Aumento de la tarifa cobrada en dólares a extranjeros por servicios telefónicos, eléctricos, de correos y de aeropuertos.

- Alza de los precios en las tiendas que operan en dólares.

- Cobro de impuestos a los trabajadores por cuen- ta propia (en primer término, mediante una cuota inicial de registro).

- Cobro de impuestos a ciudadanos que ganan en divisas.

- Probable alza de los aranceles aplicados a ciertos artículos importados, entre otros, vehículos donados (100\% del precio en dólares cobrado en antiguos pesos).

- Reducción de algunos componentes del gasto público con anterioridad a 1995 (aún no se dispone de información detallada).

Todas estas medidas deberían contribuir a atenuar la bifurcación, dado que reducirían el déficit fiscal cubierto mediante la emisión de dinero.

\section{Medidas de reforma}

Entre 1990 y mediados de 1993 se produjo una verdadera paralización del proceso de formulación de políticas públicas. Aunque la economía sufrió una fuerte contracción en ese período, no se adoptaron reformas importantes. El programa nacional de alimentos, que fue sometido a la consideración de la Asamblea Nacional en diciembre de 1990, era muy similar a las "campañas" realizadas años antes y suponía una detallada planificación de la asignación de recursos al sector agrícola. El programa dio mínimos resultados, en parte porque la contracción de la economía nacional impidió la entrada al país del gran volumen de productos importados y recursos necesarios para su ejecución. Además, la inacción del gobierno al respecto resultaba cada vez más ineficaz. Mientras tanto, los cubanos reaccionaban individualmente y sin mayor planificación a la difícil situación en que se encontraban. Entre otras cosas, comenzaron a trabajar fuera del sistema planificado formal y la economía socialista tradicional, en la mayoría de los casos realizando actividades en el sector internacionalizado que les permitían ganar dólares, desempeñando tareas lucrativas como intermediarios entre los dos sectores de la economía, haciendo transacciones en el mercado negro, o vendiendo bienes y servicios en el mercado clandestino.

Las medidas de reforma adoptadas en el segundo semestre de 1993 legitimaron la mayor parte de las actividades económicas que habían comenzado a desempeñar los cubanos. Las reformas fueron esencialmente una respuesta oficial a lo que estaba realizando la población y a la presión que ejercían los cubanos ante la falta de políticas públicas razonables, confiables o viables. Las medidas adoptadas han fortalecido el sector intemacionalizado de la economía, al posibili- 
CUADRO 2

Cuba: Principales indicadores económicos, 1985-1995

\begin{tabular}{|c|c|c|c|c|c|c|c|c|c|c|c|}
\hline & 1985 & 1986 & 1987 & 1988 & 1989 & 1990 & 1991 & 1992 & 1993 & 1994 & 1995 \\
\hline $\begin{array}{l}\text { PlB estimado (miles } \\
\text { de millones de dólares) }\end{array}$ & 32.3 & 32.6 & 31.4 & 32.2 & 32.5 & 31.5 & 23.6 & 20.3 & 18.3 & $18.4^{a}$ & $\cdots+$ \\
\hline $\begin{array}{l}\text { PIB per cápita estimado } \\
\text { (dolares) } \\
\text { Variación del PJB per }\end{array}$ & 3181 & 3182 & 3032 & 3076 & 3076 & 2971 & 2226 & 1897 & 1679 & $1640^{\mathrm{a}}$ & $\ldots$ \\
\hline cápita $(\%)$ & $(3.5)$ & - & -4.7 & 1.5 & $=$ & -3.4 & -25.1 & -14.8 & -11.5 & $-2.3^{a}$ & $\ldots$ \\
\hline $\begin{array}{l}\text { PIB per cápita, índjce } \\
\text { (CEPAL) }\end{array}$ & 100.0 & 99.7 & 95.4 & 96.5 & 96.4 & 92.5 & 68.7 & 58.6 & 52.4 & $51.8^{\mathrm{a}}$ & $\cdots$ \\
\hline $\begin{array}{l}\text { Total de exportaciones } \\
\text { (miles de millones } \\
\text { de dólares) }\end{array}$ & 5.99 & $\$ .32$ & 5.40 & 5.52 & 5.4 & 4,9 & 3.6 & 2,2 & 1.7 & $1.8^{\mathrm{a}}$ & $\ldots$ \\
\hline $\begin{array}{l}\text { Total de importaciones } \\
\text { (mites de millones } \\
\text { de dólares) }\end{array}$ & 8.04 & 7.60 & 6.58 & 6.58 & 8.1 & 6.7 & 3.7 & 2.5 & 2.2 & $2.3^{\mathrm{a}}$ & $\ldots$ \\
\hline $\begin{array}{l}\text { Deuda externa en } \\
\text { divisas (miles } \\
\text { de millones de } \\
\text { dólares) }\end{array}$ & 3.9 & 6.0 & 5.7 & 6.5 & 6.2 & 7.0 & 8.4 & 10.0 & 10.8 & $\cdots$ & $\cdots$ \\
\hline $\begin{array}{l}\text { Déficit presupuestario } \\
\text { (niles de millones } \\
\text { de pesas) }\end{array}$ & 0.3 & 0.2 & 0.6 & 1.1 & 1.4 & 2.0 & 3.7 & 4.2 & 5.1 & $1.4^{\mathrm{a}}$ & $\cdots$ \\
\hline $\begin{array}{l}\text { Porcentaje del PIB } \\
\text { estimado }\end{array}$ & 0.9 & 0.6 & 1.9 & 3.4 & 4.3 & 6.3 & 15.7 & 20.7 & 27.9 & 7.6 & $\cdots$ \\
\hline $\begin{array}{l}\text { Zafra (millones de } \\
\text { toneladas métricas) }\end{array}$ & 7.9 & 7.5 & 7.2 & 8.1 & 7.6 & 8.4 & 7.2 & 7.0 & 4.3 & 4,0 & $3.5^{\mathrm{a}}$ \\
\hline $\begin{array}{l}\text { Importaciones de } \\
\text { petróleo (millones } \\
\text { de toneladas métricas) }\end{array}$ & 13.5 & 13.2 & 13.5 & 13.4 & 13.3 & 11.6 & 9.2 & 6.2 & 5.7 & 6.2 & $\ldots$ \\
\hline $\begin{array}{l}\text { Producción de petróleo } \\
\text { (millonesde toneladas } \\
\text { métricas) }\end{array}$ & 0.9 & 0.9 & 0.9 & 0.7 & 0.7 & 0.7 & 0.5 & 0.9 & 1.1 & 1.3 & $1.4^{a}$ \\
\hline $\begin{array}{l}\text { Total petróleo (millones } \\
\text { toneladas métricas) }\end{array}$ & 14.4 & 14.1 & $\begin{array}{r}14.4 \\
.\end{array}$ & 14.1 & 14.0 & 12.3 & 9.7 & 7.1 & 6.8 & 7.5 & $\cdots$ \\
\hline \multicolumn{12}{|l|}{ Tipos de cambio } \\
\hline $\begin{array}{l}\text { Oficial para turistas } \\
\text { (pesos por dólar) }\end{array}$ & & & 1.0 & 1.0 & 1.0 & 1.0 & 1.0 & 1.0 & 1.0 & 1,0 & 1.0 \\
\hline $\begin{array}{l}\text { Oficial cometcial } \\
\text { (pesos por dólar) }\end{array}$ & & & 0.74 & 0.74 & 0.74 & 0.74 & 0.74 & 0.74 & 0.74 & 0.74 & 0.74 \\
\hline $\begin{array}{l}\text { Paralejo } \\
\text { (pesos por dólar) }^{b}\end{array}$ & & & & & 5 & $7(9)$ & $20(12)$ & $35(7)$ & $55(6)$ & $100(11)$ & $35(10)$ \\
\hline
\end{tabular}

Fuente: CoNAS, 1994; CEE, 1989; Terrero, 1994; Centro de Estudios sobre la Economía Cubana, 1995;

CEPAL, 1994.

a Estimado.

b Los números en paréntesis indican los meses. 
tar el surgimiento de lo que podría considerarse un tercer sector, aunque guarda estrecha relacion con el sector intermacionalizado. Este tercer sector es un mercado interno que opera simultáneamente con dólares y pesos, que ha reaparecido desde que comenzaron a aplicarse las medidas de reforma y que ha registrado una notable expansión desde que se promulgaron las nuevas leyes.

En virtud de la primera reforma de importancia que se introdujo en agosto de 1993, después del período de parálisis, la tenencia y el empleo de dólares por parte de los cubanos dejó de constituir un delito. La medida supuso el reconocimiento oficial y la legitimación de una práctica generalizada, pero también se tradujo en un aumento de las transacciones rutinarias en dólares porque desapareció el temor al castigo por el uso de esa moneda, lo que hasta entonces había sido el principal factor disuasivo. Es probable que la legalización del empleo de dólares y el incremento consiguiente de la demanda de dólares con fines de ahorro y para realizar transacciones hayan contribuido a su rápida apreciación entre mediados de 1993 y mediados de 1994. De todos modos, esta medida reforzó el sector dolarizado de la economía y dio respaldo al empleo de dólares en transacciones internas.

La liberalización del autoempleo en microempresas en septiembre de 1993 autorizó a quienes desempeñaban 147 tipos de actividades económicas a registrarse oficialmente, y a dejar de trabajar clandestinamente (Gobierno de Cuba, 1994a). A fines de 1994, ya se habían registrado como trabajadores independientes alrededor de 170000 personas, más de 48000 de las cuales trabajaban en La Habana (Gramma, 1995, p. 3). La expansión de este sector permitió absorber una cantidad cada vez mayor de excedentes de ingresos. Es posible que a medida que siga creciendo los precios bajen más todavía, aunque eso depende también del volumen de creación de dinero, determinado en gran medida por el déficit fiscal. La reapertura de los mercados de productos agrícolas el $1^{\circ}$ de octubre de 1995 contribuyó notablemente al fortalecimiento de los mecanismos de mercado. En las leyes sobre la materia se estipula que en dichos mercados los precios deben estar determinados por la oferta y la demanda; que deben abarcar a todos los productores agrícolas, incluidas las granjas privadas, las granjas estatales, las UBPC, las granjas del ejército, los huertos privados y diversas cooperativas; que todo el país debe constituir un mercado único integrado y que los productos agrícolas se pueden transportar libremente a toda la isla, pero que las granjas sólo pueden vender su producción en esos mercados una vez que hayan cumplido con sus obligaciones contractuales con el Estado.

En una ley conexa, promulgada el 7 de octubre de 1994, se dispone la liberalización del transporte, en ella se autoriza a todos los dueños de vehículos de tamaño mediano a suscribir contratos con las granjas para el transporte de alimentos a los mercados (Ministerio de Transporte de Cuba, 1994). Los efectos positivos de estas dos leyes han quedado rápidamente en evidencia. Se estima que en el último trimestre de 1994 un $20 \%$ de los proveedores de alimentos vendieron su producción en estos mercados y algunas estimaciones indican que el porcentaje podría ser aun más alto ( $\mathrm{Gra}$ mma International, 1994). Gracias a estos mercados, la oferta de alimentos en las áreas urbanas ha aumentado y los precios han bajado a un nivel mucho menor que el registrado en los mercados negros. La existencia de mercados agrícolas también despierta el interés de los productores por incrementar la producción, lo que permite pensar que la oferta seguirá aumentando y que los precios seguirán bajando. La legalización subsiguiente de los mercados de productos industriales y artesanales $\left(1^{\circ}\right.$ de diciembre de 1994) se basa en gran medida en la de los mercados agrícolas, aunque su crecimiento y las consecuencias de su funcionamiento han sido menos espectaculares. Por otra parte, los mercados industriales y artesanales ofrecen una gran variedad de productos a los consumidores cubanos, como cocinas a querosén, artículos de aluminio para la cocina, zapatos y prendas de vestir. Los artesanos y los artistas producen actualmente una variedad extraordinaria y cada vez mayor de artículos destinados a los turistas, pero también a los numerosos cubanos que disponen de dólares.

En resumen, la legalización del autoempleo; la apertura de mercados agrícolas, industriales, artesanales y de servicios de transporte, y la transformación de granjas estatales en cooperativas han realzado la importancia de los precios y han ampliado el alcance de la economía de mercado. Aunque este sector de la economía está estrechamente vinculado a la economía internacionalizada y dolarizada, se diferencia de esta última en que está más orientada al mercado interno y más regida por el peso. Este segmento de la economía cubana es producto, entre otras cosas, de una fusión del sector internacionalizado y dolarizado, por una parte, y del sector socialista tradicional, por otra. La persistente expansión de la economía de mercado y la creciente fusión de los dos sectores mencionados son elementos esenciales de la transición hacia una economía mixta de mercado. 
V

\section{Reunificación, transición y ajustes futuros}

En último término, la unificación de los dos sectores que integran la economía exigirá la adopción de diversas políticas públicas y cambios institucionales. Como se indica en la sección anterior, ya se han realizado importantes reformas, pero habrá que adoptar muchas otras medidas.

\section{Liberalización de empresas}

Como se indicó anteriormente, la legalización de las microempresas de trabajadores independientes y la apertura de mercados en los que pueden operar legalmente han sido medidas positivas e importantes, pero la evolución de este sector se ha visto frenada por una serie de disposiciones legales. La limitación del tamaño de las empresas a unidades de autoempleo con reconocimiento oficial $y$, en la práctica, a algunas empresas familiares, es muy restrictiva. Hay muchas actividades económicas que deben tener una mayor magnitud para ser realmente eficientes y eficaces.

En segundo lugar, en la legalización del autoempleo realizada entre septiembre de 1993 y julio de 1995 no se consideró, una amplia gama de empresas que utilizan tecnología de vanguardia, de tal modo que el proceso se limitó a actividades poco avanzadas desde el punto de vista tecnológico (Gramma, 1993, p. 5). Todas las firmas que ofrecen servicios pueden prestar importante asistencia a empresas públicas y privadas a bajo costo; se trata, entre otras, de empresas que ofrecen consultorías técnicas y de gestión, empresas de computación, oficinas de contabilidad, oficinas de abogados, empresas de comercialización, servicios de agrimensura y de oficina, y firmas de arquitectura y de exploración geologica. Para que Cuba cuente con una economía moderna y avanzada, habría que legalizar a todas las empresas de este tipo y, además, se debería autorizar a todos los profesionales, con la excepción de los médicos, a trabajar por cuenta propia. También sería conveniente que se legalizaran diversos servicios personales y algunas pequeñas industrias.

En tercer lugar, la legislación que rige el funcionamiento de las microempresas prohíbe la comercialización privada, lo que limita el alcance de sus ope- raciones porque cada productor debe encargarse de la venta de su producción. Por lo tanto, no se puede abrir tiendas en las que se ofrezca una variedad de productos de distintas fuentes.

En cuarto lugar, convendría que se enmendaran las leyes sobre propiedad, de tal modo que los comerciantes minoristas y los productores pudieran abrir tiendas y centros comerciales especializados. Cabe preguntarse si es razonable exigir que los productos agrícolas, artesanales e industriales solo se vendan en determinados locales, cuando algunos de ellos ya están funcionando al máximo de su capacidad. Sería muy conveniente que se liberalizaran las normas sobre ubicación y alquiler que se aplican a estas empresas, porque les permitiría ofrecer mejores y más variados servicios a los clientes.

En resumen, la eliminación de una serie de restricciones que dificultan el desarrollo de este sector podría contribuir a crear empleos, a elevar las condiciones de vida de los cubanos y a estimular la productividad de empresas públicas y privadas de gran tamaño, mediante la prestación de servicios comerciales, todos los cuales son objetivos prioritarios. La supresión de las limitaciones al desarrollo de este sector también facilitaría el aprendizaje de técnicas administrativas por parte de los pequeños empresarios; este proceso, que se interrumpió en los años sesenta, será de fundamental importancia cuando se normalicen las relaciones entre Cuba y los Estados Unidos, a continuación de lo cual el país recibirá a numerosos expertos en finanzas, tecnología, administración y técnicas empresariales de otigen cubano residentes en Estados Unidos.

Por último, la supresión de las restricciones es esencial para que se produzca un aumento de la demanda de pesos y de la disponibilidad de bienes y servicios, lo que a su vez redundaría en una baja de los precios determinados por el mercado y del precio del dólar en el mercado negro.

\section{Cambios institucionales}

El proceso de transición a una "economía con el mercado" exigirá una amplia gama de cambios institucio. 
nales, algunos de los cuales contribuirán considerablemente a la reunificación de la economía socialista tradicional y del sector intemacionalizado. Fuera de la liberalización de las empresas ya analizada, es posible que los cambios más importantes de esta naturaleza sean la apertura de un mercado inmobiliario, de autombviles y de otros bienes tangibles, la privatización y la cooperativización, y la reestructuración de las sociedades anónimas. Otros cambios institucionales, como la reforma de los sistemas financiero y bancario, la adopción de normas que regulen el funcionamiento del sector privado y la promulgación de nuevas leyes sobre derechos de propiedad, son factores importantes de la transición económica, aunque tal vez sean menos esenciales para la reunificación de la economía.

La legalización de los mercados de vivienda y de otros bienes tangibles sería importante per se $\mathrm{y}$, asimismo, para incrementar la demanda de pesos y contribuir a la baja del tipo de cambio en el mercado negro y de otros precios determinados por el mercado. Según la legislación vigente, el propietario de una casa sólo puede venderla en antiguos pesos al Estado, que asigna viviendas conforme a criterios políticos. También puede permutarla por dinero en efectivo en una operación informal, por lo que se podría afirmar que ya existe, en cierto sentido, un mercado inmobjliario. La mayor parte de los cubanos, probablemente un $80 \%$, son propietarios de la casa en que viven, pero no tienen derecho a vender o comprar casas a precios determinados por el mercado. Si se creara un auténtico mercado inmobiliario, los precios de las casas subirían considerablemente, y surgiría una nueva e importante fuente de demanda de antiguos pesos. En último término, esto contribuiría a la reducción del tipo de cambio en el mercado negro y atenuaría la bifurcación de la economía. La legalización de los mercados de otros bienes tangibles tendría efectos similares.

Otra reforma institucional que podría ser muy importante siempre que se realizara con mucha cautela es la privatización y cooperativización de las entidades de propiedad del Estado. Ya se ha comenzado a privatizar una gran proporción de las granjas estatales y a convertirlas en cooperativas. Hay muchos servicios estatales que funcionan en pequeña escala y que ya han comenzado a enfrentarse a la competencia de un sector independiente cada vez más extenso. Entre ellos se cuentan tiendas de distinto tipo, talleres, salones de belleza y peluquerías, bares y cafés. La privatización de estos negocios mediante su venta a ciudadanos cubanos sería una medida acertada; de hecho, permitiría que se prestaran mejores servicios, porque en esta área el Estado siempre ha tenido dificultades para asegurarse de que se prestan servicios adecuados y para adaptarse a la demanda de los consumidores. La privatización también permitiría al Estado recibir una gran cantidad de antiguos pesos, lo que limitaría su circulación, aumentaría su valor en comparación con el dólar y reduciría el precio de bienes y servicios en antiguos pesos. Las entradas que recibiría el Estado por este concepto posibilitarían una reducción del déficit fiscal y de la emisión de dinero. Todos estos efectos contribuirían a atenuar la división de la economía.

La privatización de las pequeñas y medianas empresas plantea mayores dificultades. El gobierno ya ha autorizado la privatización parcial de algunas empresas de este tipo y la venta de los activos privatizados a extranjeros mediante la creación de empresas mixtas con participación extranjera minoritaria, en muchos casos para la ejecución de proyectos de inversión. La venta de activos a extranjeros, aun mediante la creación de empresas mixtas, presenta una serie de inconvenientes, entre otros la venta de activos de alto valor a precios muy bajos y la constante remesa de utilidades fuera del país. La venta de estas empresas a cubanos podría ser una buena altemativa, pero los cubanos no podrían pagar en dólares. Tal vez convendría explorar otras alternativas, como la transformación de las empresas más grandes en cooperativas. La privatización total o parcial de monopolios "naturales", como ocurrió con la venta del $49 \%$ de la compañía de teléfonos a la firma mexicana Dormus, es aún más difícil y exige la creación de nuevos organismos públicos de control, para evitar el posible abuso del poder monopólico.

\section{Política macroeconómica}

Las políticas macroeconómicas de Cuba, incluidas las políticas fiscal, monetaria, cambiaria y de control de precios, han sido una de las principales causas de la bifurcación de la economía. En el presente ensayo no es posible analizar el tema en detalle, debido a su complejidad y su carácter polémico, pero se proponen posibles combinaciones de políticas y políticas concretas que permitirían reunificar la economía y facilitarían una evolución macroeconómica estable y sostenible.

Entre las políticas macroeconomicas que se han aplicado para hacer frente a la situación figuran la política fiscal descrita en la sección IV y la adopción 
del "peso convertible". La política fiscal tiene por objeto incrementar las entradas tributarias, recortar los gastos, reducir el déficit fiscal y, por lo tanto, la creación de dinero para financiarlo, y mitigar las presiones inflacionarias resultantes. De acuerdo con la información disponible, se podría suponer que esta política fiscal ha dado resultados satisfactorios: desde que se comenzaron a aplicar las estrictas medidas fiscales descritas, aunque también por otros motivos, el déficit fiscal ha disminuido notablemente, la emisión de dinero se ha desacelerado, y han bajado tanto el tipo de cambio en el mercado negro como los precios determinados por el mercado. Sin embargo, las proyecciones indican que el déficit fiscal seguirá siendo relativamente alto en 1995, puesto que ascenderá a alrededor del 5 a $6 \%$ del PIB (Gramma International, 1995, p. 4); por lo tanto, mientras la única alternativa para cubrir el déficit sea la emísión de dinero, las presiones inflacionarias no desaparecerán, dado que en Cuba no hay un mercado de bonos.

La creación y la emisión de nuevos pesos "convertibles", iniciadas en diciembre de 1994, forman parte de la estrategia general de sustitución de los antiguos pesos por pesos convertibles en dólares, supuestamente a la par con el dólar. En los pesos "convertibles", que están muy bien impresos, no se indica en qué son "convertibles" ni a qué tasa. Hay pocas posibilidades de que el peso "convertible" llegue a ser algo más que una moneda de uso poco frecuente, y nadie cree que pueda reemplazar a los antiguos pesos y mantener la paridad con el dólar. Hasta agosto de 1995, el Banco Central había podido mantener la convertibilidad del nuevo peso en dólares, sólo debido a que esta moneda se había comenzado a emitir poco antes, hacía solo siete meses. En el futuro va a ser difícil limitar las emisiones para que los pesos sigan siendo convertibles en dólares. La percepción de ingresos sin costo alguno mediante señoreaje es tan importante para el gobierno que probablemente no estará dispuesto a renunciar a esa posibilidad. Según mis estimaciones, a más tardar en los primeros meses de 1996 se habrá emitido una cantidad tan alta de nuevos pesos "convertibles" que no se podrán utilizar para comprar bienes y servicios en las tiendas que operan en dólares. Cuando esto suceda, la población dejará de considerar que tales pesos equivalen a dólares y perderá interés en ellos como medio de ahorro, por lo que preferirá contar con dólares. El peso "convertible" dejará de tener el mismo valor que el dólar en el mercado cambiario paralelo y su valor en dólares disminuirá. Cuba tendrá entonces tres sis- temas monetarios paralelos, lo que dará origen a nuevas complicaciones y problemas.

¿Qué políticas macroeconómicas podrían adoptarse para reunificar la economía y darle una mayor estabilidad? Las políticas esbozadas a continuación no constituyen una propuesta, sino que corresponden a áreas de acción que convendría analizar.

a) Política fiscal

- Política fiscal destinada a reducir el déficit, que ya se ha comenzado a aplicar con resultados satisfactorios.

- Nuevos aumentos de impuestos o recortes de gastos para reducir el déficit hasta un nivel manejable.

- Empleo de mecanismos para cubrir el déficit que sustituyan a la emisión de dinero; por ejemplo, venta pública de bonos.

- Sustitución de las actuales barreras no arancelarias por aranceles, lo que podría ofrecer una importante fuente de entradas durante un período de transición.

- Fijación de precios que permitan cubrir los costos de las empresas estatales, para contribuir a la reducción del déficit.

\section{b) Política monetaria}

- Urgente freno de la emisión de antiguos pesos, como un medio para seguir reduciendo la inflación.

- Emisión muy limitada de nuevos pesos "convertibles", con el único objeto de canalizar fondos hacia el gobierno mediante señoreaje, y evitar que se orienten hacia el dólar.

- Adopción de otras medidas que incrementen la demanda de antiguos pesos, y contribuyan a la baja de los precios y del tipo de cambio en el mercado negro. Entre otras, apertura de auténti$\cos$ mercados de bienes inmobiliarios, de automóviles y de otros bienes, liberalización de las empresas de acuerdo con los lineamientos indicados, y ampliación general de las funciones de los mercados.

- Drástica reducción de los antiguos pesos en circulación e incremento de su demanda, para inducir una baja de los precios determinados por el mercado y del tipo de cambio en el mercado negro.

c) Política cambiaria

- Mantenimiento de la convertibilidad de los nuevos pesos, a la par, mediante la estricta limitación de las emisiones. 
- Medidas destinadas a fomentar el empleo de antiguos pesos y a incrementar su valor en relación con el dólar en los mercados negros, es decir, incrementar la demanda de antiguos pesos.

- Inmediata igualación de los tipos de cambio con el tipo utilizado en el sector turismo; con tal objeto, se debería exigir que todas las transacciones comerciales se realicen a un tipo de cambio paritario, en lugar de a 0.74 pesos por dólar, lo que constituiría el primer paso del proceso de devaluación.

- Inicio del proceso de devaluación del antiguo peso.

- Medidas destinadas a eliminar, al cabo de tres o cuatro años, la diferencia entre el tipo de cambio oficial y el que determina el mercado.

- Unificación del peso "convertible" y el antiguo peso cuando se igualen el tipo de cambio oficial $y$ el que determina el mercado.

\section{d) Proteccionismo}

- Limitación o eliminación progresiva de la discriminación en materia de proteccionismo (disposiciones burocráticas y discrecionales), mediante la supresión de los privilegios de las sociedades anónimas consistentes en la no aplicación de aranceles ni barreras no arancelarias; la uniformación de los aranceles aplicables a todos los sectores, probablemente otorgando un trato inicial especial a los productos farmacéuticos y a algunos alimentos; y la sustitución de las barreras no arancelarias por aranceles.

- Inicio del proceso de ajuste con aranceles altos (para fines relacionados con la balanza de pagos y la captación de recursos), que se reducirían gradualmente a medida que vaya mejorando la situación del sector externo y la economía se recupere.

\section{Políticas de precios y seguridad social}

- Rápida eliminación de los controles de precios siempre que no afecte el costo de los alimentos básicos racionados.

- Alza de los precios de los demás artículos racionados, con el propósito final de eliminar el control de esos precios.

- Inicio del proceso para establecer un sistema de complementación del ingreso de las personas y familias necesitadas, que sustituya a la conce- sión de subsidios a toda la población mediante el racionamiento.

- Coordinación del establecimiento de un sistema de seguridad social y de complementación de ingresos con destinatarios específicos, y del alza y la desregulación de los precios de los artículos actualmente racionados (por ejemplo, los fondos que actualmente se asignan a la concesión de subsidios a empresas productoras de bienes racionados y con precios fijos que trabajan a pérdida podrían destinarse a la complementación de ingresos de los grupos más vulnerables).

A mi juicio, la adopción de las políticas enumeradas es importante para la reunificación de la economía y para facilitar un proceso de ajuste estructural y, en último termino, para la recuperación económica. La política cambiaria y la política comercial son muy importantes para la expansión y la diversificación de las exportaciones, como también para la sustitución de importaciones. Es esencial y urgente que se proceda a devaluar la moneda, que está extremadamente sobrevaluada, y a limitar y eliminar la acentuada discriminación que supone el sistema vigente de protección; sólo así Cuba podrá superar la grave escasez de divisas que dificulta la recuperación económica. La aplicación continuada de una estricta política fiscal, unida a la adopción de una política monetaria antiinflacionaria y creativa, podría contribuir al uso más generalizado del peso y al aumento de la demanda de esta moneda, junto con limitar el circulante. A su vez, esto redundaría en una relativa baja del tipo de cambio en el mercado negro y probablemente en una disminución de los precios determinados por el mercado; por lo tanto, modificaría los incentivos a la transferencia de recursos desde el sector socialista tradicional a los sectores internacionalizados de la economía, y los dejaría en un nivel adecuado. También es muy importante la modificación del sistema de seguridad social para que se ofrezca protección a quienes se vean afectados por los cambios de políticas, sobre todo de las relacionadas con los precios, y se complementen sus ingresos, en lugar de otorgar subsidios a toda la población a través de los productos racionados y con precios regulados. Cabe señalar que el Ministro de Finanzas de Cuba, Dr. José Luis Rodríguez, ha reconocido la necesidad de reformar el sistema de seguridad social (A. Rodríguez Drivet, 1995). 


\section{VI}

\section{Resumen y conclusiones}

En el presente ensayo se analiza la principal característica que ha presentado la economía cubana desde comienzos de la década de 1990, es decir, su división en un sector socialista tradicional regido por el peso, y un sector dolarizado y regido por el mercado. Esta bifurcación se debe a los siguientes factores: i) la rápida expansión del turismo, de la participación extranjera en empresas mixtas y de las sociedades anónimas; ii) las políticas macroeconómicas aplicadas con anterioridad a 1994, que produjeron un abultado déficit fiscal, un incremento acelerado del circulante, rápidas alzas de los precios determinados por el mercado y una drástica pérdida de valor de los antiguos pesos con respecto al dólar en los mercados paralelos, mientras la tasa oficial se mantenía invariable; iii) la política cambiaria y la política comercial, que dieron origen a una profunda discriminación en 10 que respecta al acceso a las importaciones en favor del sector internacionalizado, en particular las sociedades anónimas, y iv) la atonía general, la falta de confianza y la contracción de la economía socialista tradicional.

La bifurcación señalada influye notablemente en el funcionamiento de Ia economía cubana y en el de la sociedad en general. En primer término, ha tenido importantes efectos en la distribución del ingreso; esto se debe a que los cubanos con acceso a dólares tienen un nivel de ingresos más alto que el de los integrantes de la economía socialista tradicional que ganan en pesos, debido al elevado valor del dólar en los mercados paralelos. Esta diferencia es un incentivo muy poderoso, que atrae recursos, sobre todo recursos humanos, al sector internacionalizado. La asignación de un cierto volumen de recursos al sector de la economía que percibe ganancias en dólares es una medida atinada, pero dicho sector no debe confundirse con las actividades que generan divisas, como la producción de azúcar y de tabaco, o que producen posibles sustitutos de importaciones. Se observa que la retribución que reciben de la sociedad quienes tienen la capacidad de ganar o conseguir dólares no corresponde al valor real de su contribución a la estructura económica o social. Además, esta brecha propicia una búsqueda generalizada de lucro, puesto que se puede ganar mucho dinero mediante la venta en un sector de la economía de bienes y servicios adquiridos en el otro, aprovechando la diferencia entre los precios fijos y los determinados por el mercado, por una parte, y entre el tipo de cambio oficial y el paralelo, por otra. Además, hay diversos fenómenos sociales negativos que se ven agravados por la bifurcación.

A partir de mediados de 1993 se han adoptado diversas políticas públicas con el objeto de mitigar el problema. La legalización de las actividades independientes y la apertura de mercados de productos agrícolas, industriales y artesanales y de servicios de transporte han fortalecido la economía de mercado, parcialmente vinculada al sector internacionalizado, en el sentido de que las fuerzas de mercado determinan los precios y el ingreso de quienes la integran. Además, a partir de 1994 la política fiscal ha contribuido a desacelerar el proceso de bifurcación.

Para reunificar la economía habría que realizar profundas reformas institucionales y de políticas. Sería importante seguir liberalizando la pequeña y mediana empresa y efectuar ciertas reformas institucionales: entre otras, legalizar el mercado de la vivienda, continuar la cooperativización en los casos necesarios, y privatizar pequeñas y medianas empresas, sobre todo en la prestación de servicios y la comercialización. La adopción de estas medidas permitiría ampliar la economía de mercado y tendría efectos macroeconómicos positivos, que podrían contribuir notablemente a la reducción del tipo de cambio en el mercado negro y a la creación gradual de una estructura más adecuada de incentivos. Sin embargo, 10 más importante es la política macroeconómica (seguir reduciendo el déficit fiscal y limitar la creación de dinero), unida a las políticas cambiaria y comercial encaminadas a uniformar los tipos de cambio vigentes en el mercado negro y el oficial (probablemente a 3 pesos por dólar) y el sistema de protección, y a eliminar la marcada discriminación que supone su funcionamiento actual. También habría que desregular los precios, junto con transformar el sistema de seguridad social; éste, que actualmente otorga subsidios a toda la población mediante la regulación de los precios de los productos racionados, debería convertirse en un sistema bien focalizado de complementación del ingreso de las personas realmente necesitadas. 
Esta amplia gama de medidas institucionales y macroeconómicas también posibilitaría muchos de los cambios de políticas necesarios para realizar un ajuste estructural que dé resultados satisfactorios. La devaluación de la moneda en el contexto del tipo de cambio oficial y la uniformación de este tipo de cambio y el paralelo, unidas a una mayor liberalización de las pequeñas y medianas empresas y la supresión de la discriminación que supone la política comercial, deberían permitir un importante aumento y diversificación de la producción destinada a los mercados interno y externo. El aumento con fines de exportación y de sustitución de importaciones es esencial para que la recuperación económica del país en el futuro sea sostenida y sostenible.

Cuba recién ha iniciado el proceso de reforma institucional y de políticas necesario para que se dé un proceso de ajuste, de transición y de recuperación. $S i$ bien es encomiable que se actúe con cautela en la formulación y aplicación de políticas, es de lamentar la falta de determinación mostrada entre diciembre de 1994 y agosto de 1995 en diversas áreas. La adopción de medidas con el objeto de facilitar la recuperación económica es una tarea de gigantescas proporciones, dado que la situación actual se caracteriza por un extremo deterioro de gran parte de la infraestructura y de las instalaciones de los sectores industrial, agrícola y de servicios, que son inadecuadas desde el punto de vista del medio ambiente, suponen un gasto excesivo de energía, no permiten a Cuba tener una posición competitiva a nivel internacional y son básicamente obsoletas.

(Traducido del inglés)

\section{Bibliografía}

Báez, L. (1994): Entrevista a Raúl Castro, Gramma International, La Habana, 28 de septiembre.

Carranza, J. (1993): Cuba: los retos de la economía, Cuadernos de nuestra América, vol. IX, No 19, La Habana, Centro de Estudios sobre América (CEA).

Casanova, A. (1994): The Cuban economy: Reality and perspectives, Gramma International, La Habana, 9 de noviembre.

Casals, R. (1995): Finances are improving, Gramma lnternational, La Habana, 4 de enero.

CEE (Comité Estatal de Estadísticas) (1989): Anuario estadistico de Cuba 1988, La Habana.

Centro de Estudios sobre la Economía Cubana (1995): Presentación pública sobre ta economía cubana, La Habana, 20 y 21 de febrero, mimeo.

CEPAL (Comisión Económica para América Latina y el Caribe) (1994): Balance preliminar de la economía de América Latina y el Caribe 1994, LC/G.1846, Santiago de Chile, 20 de diciembre.

CONAS (Consultores Asociados) (1994): Cuba: inversión y negocios, La Habana.
Gobiemo de Cuba (1994a): Decreto $N^{\circ} 191$ y Resolución sobre el Mercado Agropecuario, Gramma, La Habana, 21 de septiembre.

(1994b): Decreto No192 dei Comité Ejecutivo del Consejo de Ministros, Gramma, La Habana, 26 de octubre.

Gramma (1993): La Habana, 9 de septiembre. (1995): La Habana, 14 de febrero.

Gramma International (1994): New farmers markets help alleviate food shortages, La Habana, 14 de diciembre. (1995): La habana, 4 de enero.

Lee, S. (1993): Entrevista a Carlos Lage, Gramma International. La Habana, 10 de noviembre.

Ministerio de Transporte de Cuba (1994): Resolución $N^{\circ}$ 178-94 sobre Transporte de Productos hacia los Mercados Agropecuarios, Gramma International, 7 de octubre.

Rodríguez Drivet, Arleen (1995): Entrevista a José Lais Rodríguez, Trabajadores, La Habana, 26 de febrero.

Strout, Jan (1995): Women, the politics of sexuality, and Cuba's economic crísis, mimeo,

Terrero, A. (1994): Tendencias de un ajuste, Bohemia, La Habana, octubre. 